\title{
Variação terminológica denominativa no universo da cana-de-açúcar: um estudo de fatores condicionantes
}

\section{Denominative terminological variation in the sugarcane universe: a study of conditioning factors}

Luís Henrique Serra* Mariângela de Araújo**

\footnotetext{
* Universidade Federal do Maranhão. Programa de Pós-Graduação em Letras da Universidade Federal do Maranhão, campus Bacabal. E-mail: luis.ufma@gmail.com

Universidade de São Paulo. Programa de Pós-graduação em Filologia e Lingua Portuguesa. E-mail: armariangela@yahoo.com.br
} 
Resumo: Este artigo apresenta os resultados preliminares de um estudo sobre a variação terminológica no universo da cana-de-açúcar no Brasil. O estudo toma como pressuposto teóricometodológico, sobretudo, a Teoria Comunicativa da Terminologia (CABRÉ 1999, 2003) e o modelo teórico da variação terminológica de Freixa $(2002,2013)$, que apresenta seis causas para a variação terminológica. A partir desses pressupostos, o estudo utiliza-se de um corpus com características diversificadas: textos orais produzidos por especialistas com alto grau de especialização, atuando em diferentes contextos comunicativos, como entrevistas televisionadas, palestras e aulas; textos escritos de diferentes gêneros, também elaborados por especialistas, como artigos científicos, apostilas de curso de Agronomia, relatórios técnicos, páginas eletrônicas do setor sucroalcooleiro, teses e dissertações. A pesquisa cruza diferentes fatores de variação e tenta apresentar os mais relevantes para a variação terminológica denominativa.

Palavras-chave: Variação terminológica denominativa; Fatores da variação terminológica; Texto terminológico; Cana-de-açúcar.

Abstract: This paper presents the preliminary results of a research about the terminological variation in Brazilian sugarcane universe. The study takes as foundation mainly the Communicative Theory of Terminology (CABRÉ 1999, 2003) and the terminological variation model by Freixa $(2002,2013)$, that presents six terminological variation causes. From those assumptions, the study uses a corpus with different feats: oral texts produced by specialists with high level of specialization, acting in different communicative contexts, like televised interviews, lecture and classes; whiten texts of different genres prepare by specialists, like articles, Agronomist school books, technical reports, websites of alcohol sector, thesis and dissertations. The research hinges different variation factors and try presents the more relevance to terminological and denominative variation.

Keywords: Terminological Denominative Variation; Terminological Variation Factors; Terminological Text; Sugarcane. 


\section{Introdução}

Este é um estudo sobre a variação denominativa em discursos especializados sobre a cana-de-açúcar. 0 trabalho parte do pressuposto de que a língua, em contexto profissional, é também permeada pela variação linguística; portanto, toma como pressuposto teórico e metodológico as teorias que partem de uma Terminologia descritiva, sobretudo a Teoria Comunicativa da Terminologia, de modo a afirmar que a língua em contexto comunicacional técnico-especializado varia tanto no âmbito das denominações dadas aos conceitos quanto no próprio nível conceitual. Considerando essa premissa, o estudo também entende que toda variação é motivada por fatores internos ao discurso ou à língua e fatores externos, que estão relacionados ao contexto comunicacional.

Para comprovar essas ideias, a pesquisa utiliza-se de dados linguísticos do universo da cana-de-açúcar no Brasil. O corpus do estudo é composto por textos, orais e escritos, de diferentes gêneros textuais e destinados a públicos-alvo diversos, para observar os fatores linguísticos e extralinguísticos que condicionam a variação nesse universo. Busca-se observar quais são os fatores que têm mais peso ou relevância na variação denominativa encontrada em textos produzidos por engenheiros agrônomos especialistas em cana-de-açúcar. Considerando as dimensões deste texto, serão apresentados os resultados de uma parte do estudo.

Este estudo colabora com as discussões sobre a variação denominativa nos discursos especializados e colabora com o debate sobre os fatores que condicionam a variação terminológica em língua portuguesa. Busca apresentar uma sugestão de trabalho de pesquisa terminológica em gêneros textuais acadêmicos, considerando, principalmente, práticas comunicativas da comunidade de especialistas como fator de variação terminológica, e oferecendo, com isso, outras possibilidades de pesquisa em língua portuguesa do Brasil.

\section{Variação terminológica: múltiplas abordagens}

Entende-se como variação terminológica a existência de mais de uma denominação para um conceito ou de mais de um conceito para duas ou mais denominações em um discurso especializado, ou seja, em um evento comunicativo 
ocorrido em ambiente técnico-especializado, ou uma comunicação entre especialistas. Assim, a variação em Terminologia tem duas perspectivas: a denominativa e a conceitual. Considera-se, como faz Freixa, que a variação denominativa é um tipo específico de variação em que "a uma mesma noção correspondem diversas denominações” (2002: 54, tradução nossa) ${ }^{1}$.

A ideia da variação linguística ainda é recente dentro do campo da Terminologia, tendo sido considerado um fenômeno natural graças aos esforços de terminólogos com orientações linguísticas, sobretudo à luz da teoria da variação linguística laboviana e dos estudos sociofuncionalistas, que buscavam explicar os fenômenos existentes nos discursos especializados. Nesse sentido, a colaboração da Socioterminologia (GAUDIN 1993) e da Teoria Comunicativa da Terminologia (CABRÉ 1999, 2003) foi fundamental para o desenvolvimento de uma mentalidade variacionista dentro dos estudos terminológicos. A partir dessas perspectivas, muitas outras abordagens sobre a variação terminológica foram desenvolvidas no escopo da Terminologia descritiva e deram maior abrangência teórica e metodológica à Terminologia para explicar muitos dos fenômenos próprios da comunicação especializada. Neste estudo, serão levadas em consideração as abordagens textualistas da variação terminológica no campo da Terminologia Textual (CIAPUsCIO 2002; KOCOUREK 1991), que trata do texto especializado e seu papel dentro da variação denominativa, e da Teoria Comunicativa da Terminologia e suas reverberações (FrEIXA 2002), que se ocupam das razões da variação terminológica e de análises dos fatores condicionantes das variações denominativas e conceituais.

$\mathrm{Na}$ Terminologia de perspectiva textual, o texto especializado é entendido como o âmbito em que o termo se configura e a atividade dentro do universo especializado em que ele acontece de modo real e não idealizado. Nesse sentido, a Terminologia Textual entende o texto como

Recurso primordial de construção de conhecimento, cujas formas, estruturas e conteúdos, funcionalidades, etc. respondem ao desenvolvimento sociocultural e, portanto, muito além dos sistemas linguísticos particulares, podendo exibir, nos níveis mais globais (gênero, estilo, etc.), características específicas devido à sociedade ou à comunidade particular em que são constituídos e empregados ${ }^{2}$. (CIAPUSCIO

\footnotetext{
${ }^{1}$ As traduções feitas neste trabalho foram feitas pelos autores. No original: "el fenomen pel qual a una mateixa noció li corresponen diverses denominacions."

2 No original: "Recursos primordiales de constitución de conocimiento, cuyas formas, estructuras, contenidos, funcionalidades, etc, responden a desarrollos socio-culturales y, por lo tanto, más allá de los
} 
2003: 23)

A partir da Terminologia de perspectiva textual, discussões sobre as configurações do discurso especializado, os gêneros textuais dos contextos especializados e os níveis de especialização passam a ser realizadas. Essas discussões colaboram para a compreensão dos fatores que condicionam a variação denominativa no corpus analisado neste estudo.

A Terminologia Variacionista, que se ocupa da variação denominativa e conceitual, é outra abordagem importante, sobretudo as reflexões apresentadas por Freixa (2002), que propõe um modelo teórico-metodológico para a variação terminológica. A autora entende que toda variação está condicionada por fatores que são internos e externos ao discurso especializado e essas causas podem ser organizadas em 6 grandes grupos, que são: causas prévias, dialetais, funcionais, discursivas, interlinguísticas e cognitivas ${ }^{3}$.

Em Terminologia, a variação funcional é entendida como a variação denominativa ou conceitual relacionada aos elementos que intervêm no processo comunicativo, tanto em sua produção quanto em sua recepção. A partir desses elementos, é possível considerar uma variação que ocorre em duas distintas direções: horizontal e vertical. A perspectiva vertical está associada à relação entre especialistas com nível de conhecimento diferentes e a horizontal acontece na relação entre especialistas com o mesmo nível de conhecimento sobre um tema (CABRÉ 1999). Dentre as causas funcionais, Freixa (2002) relaciona o contexto comunicativo em que um especialista se relaciona com outros especialistas, o canal comunicativo e o tema tratado na comunicação. Sobre a variação funcional, Freixa (2006: 57) explica que “um autor pode expressar conhecimento especializado de diferentes modos, sempre de acordo com o conhecimento que ele pressupõe que seu receptor tenha"4.

sistemas lingüísticos particulares, pueden exhibir en los niveles más globales (género, estilos, etc.) características específicas debidas a la sociedad o comunidad particular en que son constituidos e empleados."

3 Em Freixa (2013), a autora propôs algumas modificações em seu modelo teórico, reorganizando essas causas. No entanto, por ainda não ter apresentado um modelo que substitua o que é utilizado neste texto, adotaremos o modelo apresentado em 2002 e reforçado em 2006 (FREIXA 2006).

${ }^{4}$ No original: "It is assumed that an author may express specialized knowledge in different ways according to the knowledge he presupposes in the recipient." 
A partir dessas considerações, este estudo busca analisar a variação denominativa no discurso especializado, oral e escrito, de engenheiros agrônomos especializados na área da cana-de-açúcar. Desse modo, aspectos como canal comunicativo, contexto comunicativo e alguns fatores linguísticos do texto e do léxico especializado também serão analisados. A perspectiva funcionalista tem ganhado espaço nos estudos terminológicos no Brasil, a exemplo do trabalho de Fetter (2017), que analisa as unidades terminológicas de textos de divulgação e técnicos da Associação Riograndense de Empreendimentos de Assistência Técnica e Extensão Rural e da Empresa Brasileira de Pesquisa Agropecuária (EMBRAPA) a partir dos princípios da gramática funcional, mostrando outra possibilidade de análise do texto especializado com a perspectiva teórica funcionalista.

\section{Metodologia do estudo}

Este estudo utiliza-se de corpora diversificados, para observar o maior número de fatores possível relacionados ao funcionamento real da linguagem especializada. Nesse sentido, três textos orais e três textos escritos especializados, de diferentes contextos e graus de especialização, serão utilizados para exemplificar as discussões que estão sendo tecidas neste trabalho. Os graus de especialização que estão sendo analisados neste estudo são: altamente especializado ou acadêmico-profissional, semi-especializado ou didático e leigo ou de divulgação. Dessa forma, os gêneros analisados estão organizados da seguinte forma:

- Altamente especializado ou profissional: 1 conferência e 1 artigo científico;

- Semi-especializado ou didático: 1 aula e 1 apostila utilizada em curso de graduação;

- Divulgação: 1 entrevista em programa de televisão e 1 artigo publicado em site de divulgação do setor sucroalcooleiro.

Os textos escritos utilizados neste trabalho são textos originários de artigos de revistas científicas da área da Engenharia Agronômica, como a Agrícola - Revista Brasileira de Engenharia Agrícola. O texto utilizado neste estudo é oriundo desse periódico; a apostila é utilizada em cursos de Engenharia Agronômica na disciplina de "Cultura da cana-de-açúcar e produção de açúcar e álcool”, do curso a distância oferecido pelo Instituto Federal de Ensino de Estados do Nordeste e Sudeste, como 
Pernambuco e São Paulo. 0 texto escrito de divulgação é oriundo do site de notícias do setor canavieiro novacana.com; o texto oral é a transcrição de uma entrevista em um programa de divulgação científica da Universidade Federal de Goiás, Programa Viver Ciência, com especialistas em cana-de-açúcar. A entrevista está disponível no YouTube ${ }^{5}$, da companhia Google. Os textos orais usados são vídeos de instituições de ensino, indústrias e centros de pesquisa de instituições brasileiras: são produzidos por engenheiros agrônomos reconhecidos na área e que pesquisam e trabalham com o plantio de cana-de-açúcar há muito tempo.

0 quadro a seguir mostra cada gênero e a quantidade de palavras dos corpora que estão sendo analisados neste estudo. É importante destacar que a quantidade de palavras é um dos objetos do nosso estudo, uma vez esse dado é um dos elementos que formam as condições de produção de um especialista. Nesse sentido, é importante saber até que ponto a condição de produção de um texto (público-alvo, oralidade e escrita, quantidade de palavras que pode ser usada em um texto e o gênero textual) condicionam a variação encontrada nele.

Quadro 1: Características dos corpora analisados

\begin{tabular}{|c|c|c|c|}
\hline Materialização & Gênero Textual & $\begin{array}{c}\text { Quantidade de } \\
\text { palavras }\end{array}$ & Total \\
& Palestra & 4.532 & \\
& Aula & 5.916 & 13.807 \\
& Entrevista & 3.359 & \\
\multirow{2}{*}{ Escrita } & Artigo & 4.194 & \\
& Apostila & 8.670 & 15.080 \\
& Artigo de & 2.216 & \\
\hline \multicolumn{2}{|c|}{ TOTAL DE PALAVRAS NO CORPUS } & \multicolumn{2}{|c|}{28.887} \\
\hline
\end{tabular}

Fonte: elaboração própria

Como se observa, a quantidade de palavras entre os textos orais e escritos é diferente entre si, muito embora os totais mostrem que a diferença não é tão notável. A apostila apresenta-se como o gênero com maior número de palavras e o artigo de

\footnotetext{
${ }^{5}$ Disponivel em: https://www.youtube.com/watch?v=XCU-gsoF0k4 $\mathrm{m}$
} 
divulgação o que tem o menor número. Apesar de ser relevante a diferença de quantidade de palavras, é necessário que se esclareça que a escolha por esses gêneros se dá por conta de uma série de justificativas que estão atreladas à própria natureza da pesquisa, ou seja, a relevância que esses gêneros dos discursos especializados têm na sociedade. Em pesquisa semelhante, Seghezzi (2011) encontra a mesma situação, de número de palavras díspares entre os gêneros de suas análises. A autora justifica esse fato afirmando que outros fatores mais relevantes, além da quantidade de palavras, permitem esse tipo de pesquisa comparativa. Nesse sentido, é importante frisar a diferença entre o texto oral e o escrito, que apresentam condições de produção e dimensões completamente diferentes e que precisam ser consideradas em pesquisas que tratem dessas diferenças. Embora essas modalidades devam ser consideradas dentro de um contínuo, ideia amplamente aceita pela Linguística Textual ( $\mathrm{KoCH} 2015)$ e pela Terminologia (SEGHEZZ, 2011; FREIXA 2002), Koch (2015b: 43) comenta que: “A observação de fatos específicos de texto falado [...] mostra que, embora utilizem, evidentemente, do mesmo sistema linguístico, fala e escrita são duas modalidades de uso da língua possuindo cada uma delas características próprias [...]”. Mesmo entendendo desse modo, a autora faz a seguinte ressalva:

Isso não significa, porém, que fala e escrita devam ser vistas de forma dicotômica, estanque, como era comum até há algum tempo e, por vezes, acontece ainda hoje. Vem-se postulando que os diversos tipos de práticas sociais de produção textual se situam ao longo de um contínuo tipológico, em cujas extremidades estariam, de um lado, a escrita formal e, de outro, a conversação espontânea. (KoCH 2015b: 43)

Como se observa, existe uma complexidade que é própria da natureza das modalidades da língua: ao mesmo tempo que têm características próprias, devem ser consideradas dentro de um contínuo tipológico, tendo em vista as diferentes realidades comunicativas em que são empregadas. Uma pesquisa que considera a realidade linguística e o uso real da língua não pode negligenciar essa realidade. A escolha dos gêneros a serem analisados ocorreu por serem exemplares de contextos comunicativos do universo da cana-de-açúcar.

Além dessas considerações, a escolha de um campo conceitual, plantação, nos permitiu certa homogeneidade nos dados, tendo em vista que o campo conceitual limita a quantidade e as unidades terminológicas que devem ser consideradas na análise. Assim, no discurso especializado dos especialistas do universo da cana-de-açúcar e que 
produziram os textos analisados, foi feito um recorte conceitual para que pudéssemos ter condições de análise desses diferentes tipos e gêneros textuais. A partir disso, só será analisado o campo conceitual plantação. Dentro desse campo, muitas temáticas podem estar encerradas, como preparo do solo, morfologia da planta, o plantio da canade-açúcar, preparo do canavial para o corte, pragas e doenças da plantação de cana e melhoramento genético da cana-de-açúcar. Desse modo, as unidades terminológicas analisadas estão organizadas em uma dessas temáticas do campo conceitual plantação.

Outro elemento que precisa ser analisado aqui é a concepção de denominação adotada no estudo, que é a de denominação discursiva. Nessa concepção, parte-se da premissa de que a denominação é um fenômeno linguístico complexo que tem diferentes fases. A denominação, a partir disso, pode ser considerada dentro de uma concepção ampla: qualquer forma linguística que está associada ao conceito pode ser considerada como uma denominação, atendendo a uma necessidade que é discursiva e funcional, pois um especialista nem sempre recorre às formas lexicalizadas para se referir a um conceito, podendo usar paráfrases e generalizações, entre outros recursos, dependendo sempre do público-alvo e da necessidade discursiva em jogo. Quando se trabalha com textos e concepções funcionalistas que têm no uso a própria estrutura da língua, é necessário que se tenha uma visão mais ampla do fenômeno da denominação. Seghezzi (2011: 82) explica que:

As denominações discursivas nem sempre cumprem os requisitos básicos de uma lexicalização, posto que geralmente, apresentam uma forma descritiva, com frequência escassa devido ao seu uso e ocasião, e, por esse motivo, não estão documentadas em obras lexicográficas ou textuais de referência. Não obstante, tais unidades, criadas no discurso, respondem a um motivo ou uma finalidade concreta, evidenciando o uso real da terminologia por parte dos especialistas e consideramos que não devem ser desvalorizadas porque representam um grande interesse para a descrição da variação terminológica. ${ }^{6}$

A partir dessas considerações, foram realizados diferentes processamentos dos textos dos corpora para efetivar a análise:

\footnotetext{
6 No original: “Las denominaciones discursivas no suelen cumplir con los requisitos básicos de lexicalización, puesto que por lo general presentan una forma descriptiva, su frecuencia es escasa a raíz de su uso y ocasional, $\mathrm{y}$, por tal motivo, no están documentada en obras lexicográficas o textuales de referencia. No obstante, tales unidades, creadas en el discurso, responden en un motivo o una finalidad concreta, evidenciando el uso real de la terminología por parte de los especialistas y consideramos que no deben ser desestimadas porque presentan un gran interés para la descripción de la variación terminológica" (SEGHEZZI 2011: 82)
} 
1. Homogeneização das configurações dos textos: os textos que se encontravam em formato .PDF foram transformados em formato .TXT, para que pudessem ser editados, sendo retiradas informações como nome dos autores, abstract e títulos em inglês, além de números das revistas, das edições e das páginas, nome das universidades e das instituições, entre outros dados. Os textos orais foram transcritos considerando a ortografia vigente, sendo desconsiderados, no entanto, alguns elementos próprios do texto falado, como hesitações, interrupções e itens que não foram pronunciados com muita clareza.

2. Os textos, após ediçao, foram tratados por meio do programa computacional Antconc. Utilizando-se as ferramentas Wordlist, Concordance e File View, disponíveis no suíte do programa, foi possível criar uma lista de palavras dos corpora, de onde foram retirados os conceitos e variantes do campo plantação. Para identificação dos conceitos ${ }^{7}$ e das denominações variantes, como não foi possível contar com a colaboração de especialistas da área, foram utilizados materiais de referência (dicionários terminológicos da área da engenharia agronômica), além de materiais didáticos e o contexto em que as denominações surgiam.

3. Os conceitos e termos encontrados nos textos foram organizados em grupos, em três grandes tabelas: especializado, didático e divulgação.

Para a análise, será considerado o índice de variação denominativa dos conceitos, ou seja, a razão entre a quantidade de denominações e a quantidade de conceitos presentes nos diferentes textos analisados: quanto mais perto de 2 denominações a cada conceito presente em um determinado texto, maior é a variação denominativa presente nele. A variação será analisada a partir dos índices de variação denominativa apresentados em cada texto analisado no estudo. Para efeito de comparação entre os diferentes textos e suas diferentes características, foram elencados 60 conceitos encontrados nos textos analisados neste estudo. Após esses procedimentos, realizou-se a análise linguística. 0 que foi descrito até aqui não é uma metodologia nova ou pouco conhecida em estudos de Terminologia.

\footnotetext{
7 É importante estabelecer que o termo conceito, neste estudo, é entendido como unidade de conhecimento em construção dentro de um universo especializado, estabelecido e reconhecido pela comunidade de especialistas que habitam um universo especializado.
} 


\section{Variação Denominativa no Discurso da Cana: algumas análises}

Para mostrar como a variação denominativa se apresenta nos diferentes tipos de textos e contextos comunicativos do universo da cana-de-açúcar, no campo plantação, serão apresentadas algumas análises relacionadas à quantidade de denominações por conceito e à relevância dessa denominação dentro de cada gênero textual. Os pesos serão comparados e analisados à luz do próprio contexto em que são produzidos os textos. A análise levará em consideração alguns conhecimentos gerais sobre os gêneros textuais em questão e os contextos comunicativos em que eles são produzidos.

Após a análise da quantidade de variação, será apresentada uma visão geral acerca dos fenômenos linguísticos mais comuns encontrados nas diferentes denominações, para que se possa compreender como a variação denominativa se configura nas diferentes denominações encontradas nos corpora deste estudo.

\subsection{A variação denominativa: números gerais}

Os corpora do estudo são constituídos, no geral, por 60 conceitos e 102 denominações, o que representa um índice de variação denominativa de 1,7, indicando que cada conceito apresenta 1,7 denominações. Em outras palavras, isso significa, a princípio, que todos os conceitos dos corpora recebem mais de uma denominação. No entanto, embora o valor geral do índice ateste essa variação, é necessário observar detalhadamente as diferentes nuances dessa variação, pois, em um estudo minucioso, verifica-se que alguns conceitos não apresentam variação enquanto outros chegam a números superiores a dois. A seguir, são apresentados alguns detalhamentos da distribuição dessa variação encontrada no corpus.

O processamento dos corpora analisados levou à observação da variação denominativa desses conceitos, que foram analisados separadamente por tipo textual. 0 quadro a seguir apresenta o índice de variação de cada um dos textos analisados para este estudo.

Quadro 2: índice de variação

\begin{tabular}{|l|ll|}
\hline Modalidade & Gênero & Índice de variação \\
\hline
\end{tabular}




\begin{tabular}{|c|cc|}
\cline { 2 - 3 } Oralidade & Conferência & 1,6 \\
\cline { 2 - 3 } & Aula & 1,4 \\
\cline { 2 - 3 } & Entrevista & 2 \\
\hline \multirow{4}{*}{ Escrita } & Artigo Científico & 1,6 \\
\cline { 2 - 3 } & Apostila & 2 \\
\cline { 2 - 3 } & Artigo de Divulgação & 1,5 \\
\hline
\end{tabular}

Fonte: elaboração própria

Como se observa no quadro 2 , a variação denominativa é uma realidade em todos os textos investigados, o que demonstra e atesta essa variação nesse discurso especializado, em suas diferentes expressões. No entanto, é curioso observar que a variação aparece em diferentes níveis nos diversificados textos analisados, o que, provavelmente, é motivado pelos diferentes fatores extralinguísticos e linguísticos que condicionam os discursos dos especialistas nos diferentes gêneros utilizados. No quadro, a grande maioria tem índice de variação por conceito de mais de 1,5 em cada um dos textos. Os textos apresentam índices altos (2) e razoáveis $(1,5$ e 1,6) de variação denominativa. A partir desses resultados, não é possível afirmar que o gênero textual e 0 nível de especialização dos diferentes discursos sejam fatores relevantes dentro da amostra apresentada, uma vez que índices altos de variação denominativa (2) podem ser encontrados em gêneros com nível de especialização diferentes e que têm materialização diversa (apostila e entrevista); além disso, gêneros com maior índice de especialização apresentaram índice igual de variação $(1,6)$, superando, dentro da escala do índice de variação denominativa, outros menos especializados, como o artigo de divulgação e a aula.

Para uma melhor explicação desses índices e para a colaboração com a discussão sobre em que gênero os especialistas têm variado mais, é necessário, no entanto, observar mais de perto como essa variação acontece em cada gênero analisado. A partir disso, no quadro 3 , a seguir, é possível ver os conceitos organizados em grupos e número de denominações. Por meio desse quadro, é possível destacar como os conceitos dentro desse discurso apresentam-se em quantidade de denominação. Observar essas quantidades permite verificar a naturalidade da variação denominativa no universo discursivo da cana-de-açúcar. 0 quadro 3 está organizado da seguinte forma: na 
primeira coluna, encontram-se os gêneros que compõem o corpus; nas cinco colunas seguintes, aparece o número de conceitos que receberam 1, 2, 3, 4 ou 6 denominações no corpus em estudo; na sétima coluna, encontra-se o número total de denominações por gênero; na última coluna, aparece o número de denominações por canal comunicativo (oral e escrito).

Quadro 3: Número de conceitos por grupo de denominações

\begin{tabular}{|c|c|c|c|c|c|c|c|}
\hline $\begin{array}{l}\text { Gênero do } \\
\text { Corpus }\end{array}$ & $\begin{array}{c}1 \\
\text { DEN }\end{array}$ & $\begin{array}{c}2 \\
\text { DEN }\end{array}$ & $\begin{array}{c}3 \\
\text { DEN }\end{array}$ & $\begin{array}{c}4 \\
\text { DEN }\end{array}$ & $\begin{array}{c}6 \\
\text { DEN }\end{array}$ & $\begin{array}{c}\text { TOTAL DE } \\
\text { DENOMINAÇÃO } \\
\text { POR GÊNERO }\end{array}$ & $\begin{array}{l}\text { TOTAL POR } \\
\text { CANAL } \\
\text { (oral e } \\
\text { escrito) }\end{array}$ \\
\hline CONFERÊNCIA & 5 & 4 & 1 & & & 16 & \\
\hline AULA & 6 & 4 & & & & 14 & \\
\hline ENTREVISTA & 5 & 1 & 3 & 1 & & 20 & 50 \\
\hline$\overline{A R T I G O}$ & 6 & 3 & & 1 & & 16 & \\
\hline APOSTILA & 3 & 6 & & & 1 & 21 & \\
\hline ARTIGO DE DIV & 5 & 5 & & & & 15 & 52 \\
\hline $\begin{array}{c}\text { TOTAL DE } \\
\text { DENOMINAÇÕES } \\
\text { DA AMOSTRA }\end{array}$ & & & & & & 102 & \\
\hline
\end{tabular}

Fonte: elaboração própria

0 quadro 3 mostra que os gêneros escritos apresentam um número superior de denominações em comparação aos textos dos gêneros orais, embora a diferença entre ambos seja de apenas 2 denominações, ou seja, 1,9\% do total de denominações encontradas no corpus. Note-se que $50 \%$ dos conceitos identificados nos corpora são monodenominativos, ou seja, recebem apenas uma denominação, e 38\% dos termos recebem duas denominações, ou seja, são bidenominativos. Apenas $11 \%$ dos conceitos analisados são polidenominativos, ou seja, recebem mais de duas denominações. Isso tem relação com o próprio estilo especializado, que prima pela precisão conceitual (CABRÉ 1999), o que leva à predominância de conceitos monodenominativos. Quando se associam os conceitos polidenominativos aos bidenomiativos, o percentual de conceitos com mais de uma denominação sobe para a metade dos conceitos analisados (50\%), indicando que a variação denominativa é uma realidade considerável nessa amostra. Os gêneros aula (oral) e artigo científico (escrita) apresentam uma maior porcentagem de conceitos monodenominativos, com uma também discreta alta para o gênero escrito, 
que apresenta maior número de conceitos monodenominativos do que a aula. Cumpre considerar que ambos os gêneros têm um público-alvo com níveis de conhecimento diferentes; desse modo, o conhecimento prévio de um especialista com maior nível de conhecimento sobre o assunto permite que ele conheça as diferentes denominações sobre aquele assunto.

$\mathrm{Na}$ aula, por conta da grande gama de conteúdos sobre um assunto geral, o professor precisa ser conciso e, ao mesmo tempo, tentar apresentar diferentes aspectos de uma temática o mais rápido possível, para que todos os temas relacionados ao tema central possam caber em seu discurso. Além disso, ele conta com o material de apoio para sanar as possíveis dúvidas dos alunos sobre as questões que possam aparecer. $\mathrm{Na}$ aula em questão, o professor trata das diferentes maneiras de cultivar a cana-de-açúcar no canavial, no processo de plantio. Na aula de um curso superior em agronomia, por exemplo, muitos detalhes precisariam ser discutidos e o professor busca mostrar aos alunos as diferentes formas de denominar as diversas espécies de cana-de-açúcar. No trecho da transcrição da aula que está sendo analisada, observa-se que o professor prefere o termo "variedade" em vez de repetir outro mais comum, como "cana-deaçúcar” ou a mais popular "cana”, mostrando como o professor busca pela precisão conceitual e denominativa:

As <variedade>s, existem diversas <variedades>, mas saber alocar a <variedade> no lugar certo, no ambiente de produção correto de acordo com que ela pede, ela exige isso, é um trabalho muito importante que deve ser feito pelos profissionais que trabalham no setor de cana-de-açúcar em relação ao manejo varietal, já que a <variedade>, a <cana-de-açúcar>, é o início de tudo, onde tudo começa... Saber alocar as <variedades> no local certo, de acordo com o que ela exige, já é um grande passo para o sucesso do seu trabalho. Então, vamos começar aqui falando um pouco sobre as principais <variedades> novas, os últimos lançamentos, não assim focando nas <canas>, nas <variedades>, antigas, mas sim trazendo as <variedades> novas e isso que interessa para gente, é trazer coisa nova, aprender coisa nova

Como se observa no trecho, o professor em questão busca, conforme comenta em outro trecho da aula, pela precisão dos conceitos, para que os alunos não utilizem termos populares e confundam os conteúdos. É importante frisar que, embora se utilize muito mais o termo "variedade", é possível observar o uso de outras variantes, como “cana” e "cana-de-açúcar" para o conceito de "tipo de planta cultivada no canavial”. 
Por outro lado, o gênero entrevista apresenta o maior número de conceitos variáveis (50\% são polidenominativos). Isso acontece, provavelmente, devido à necessidade de explicações dos conceitos mais abstratos (na entrevista em questão, está sendo exposto o tema "melhoramento genético de cana-de-açúcar para o plantio") ao público leigo. No trecho a seguir, o especialista que está sendo entrevistado explica alguns conceitos especializados sobre uma nova técnica de plantio de cana-de-açúcar e opta pelo uso variante entre os termos “planta” e "cana-de-açúcar”.

\begin{abstract}
Bem, os nutrientes que são mais exigidos pela cultura da <cana-de-açúcar> são os chamados macronutrientes primários, que são nitrogênio, fósforo e potássio. Entre os três, o potássio e o nitrogênio têm grande demanda. Então, esses elementos precisam ser fornecidos para a <planta>, para ela ter um bom desenvolvimento. E a primeira ação é fazer uma adubação orgânica no plantio, para o desenvolvimento inicial, logo após o plantio. E, posteriormente, adubação por cobertura com compostagem também. Um outro insumo bastante empregado é um resíduo da indústria da <cana-de-açúcar> é a vinhaça. Ela é muito rica em potássio, então, a aplicação da vinhaça repõe esse potássio que é extraído pela cultura da <cana-de-açúcar> e nas culturas orgânicas é empregada, né? Então, é uma forma de estar reciclando o produto no processo produtivo.
\end{abstract}

No quadro 2, foi possível observar que a diferença da variação denominativa entre os três gêneros orais escritos é quase inexistente, todos têm índices parecidos ou próximos, com leves diferenças, embora seja preciso notar que os gêneros conferência e apostila apresentem conceitos polidenominativos com mais de 2 denominações. Por outro lado, os textos de divulgação têm uma quantidade de denominações maior, elevando o índice de variação nesse discurso, com um destaque à entrevista, que apresenta conceitos com mais de duas denominações.

\title{
4.2. A variação lexical: as formas da variação denominativa
}

Como foi explicado anteriormente, o conceito de denominação deve ser entendido dentro de um processo e de um contínuo em que nem sempre a forma mais precisa e mais aceita é a forma escolhida pelo especialista para se referir a um determinado conceito. Isso implica, diretamente, no que se entende por denominação. O trabalho terminológico, quando adota a perspectiva descritiva, entende que, quando se utilizam textos de usos complexos, reais e válidos, a denominação também não é uma 
questão simples e de fácil definição, razão pela qual foi feita uma delimitação relacionada à classe de palavras, tendo em vista que, nessa concepção, não apenas os substantivos podem ser considerados como forma padrão da denominação, mas também outras classes, como adjetivos, verbos e advérbios; na pesquisa, só serão consideradas as denominações que podem ser incluídas dentro da classe dos substantivos, que é a mais representativa, e dos verbos, pois se está tratando de um campo em que existem muitos processos que são explicados por verbos especializados, embora seja notória a distinção entre a quantidade de verbos e substantivos.

No gráfico a seguir, produzido com a ajuda do software livre LínguaKit ${ }^{8}$, podemse observar as classes de palavras mais comuns em todos os textos que estão sendo analisados neste estudo. Há uma predominância relevante de substantivos em relação a outras classes; a segunda classe mais utilizada é a dos verbos, seguida dos adjetivos. Há uma considerável presença de advérbios também, que intensificam e modificam os verbos especializados. É importante frisar, no entanto, que não estão sendo contadas as palavras gramaticais.

Gráfico 1: Classe de palavras nos corpora

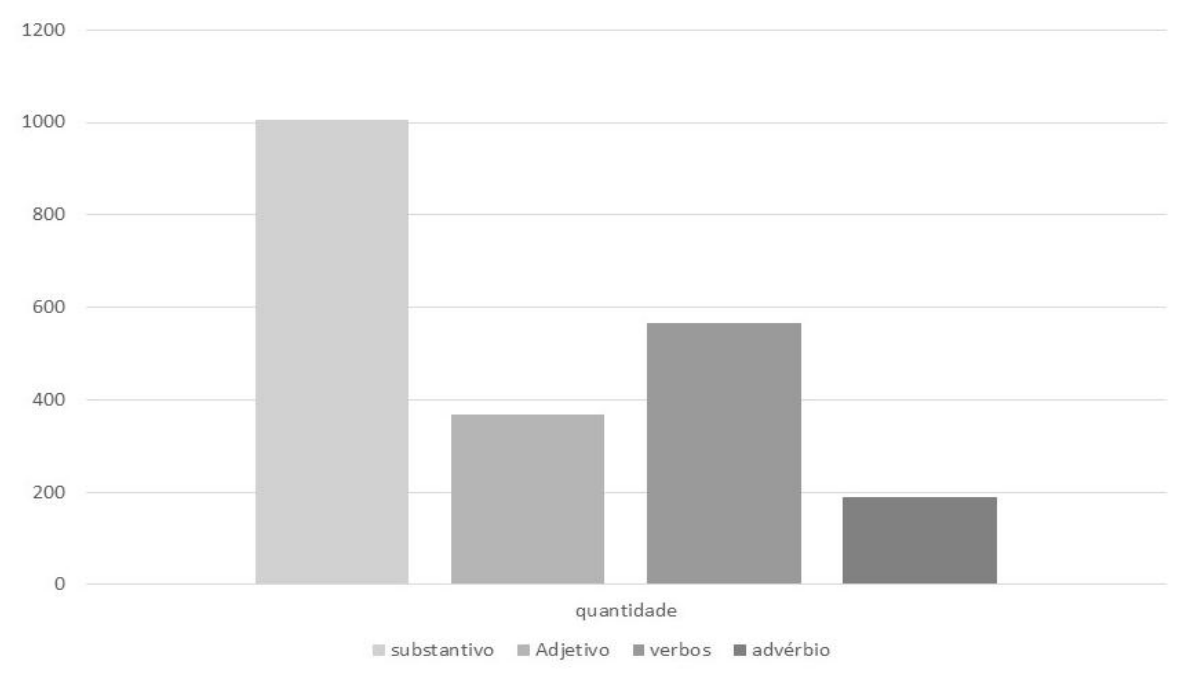

\footnotetext{
${ }^{8} 0$ software LinguaKit é um software em formato de suíte, que contém um conjunto de ferramentas gratuitas de processamento de textos online. Gamallo e Garcia (2017: 19) afirmam que o LinguaKit é "um pacote de ferramentas multilíngues para o processamento da linguagem natural (PNL) que contém modos de análise, extração, anotação e correção linguística". O programa está disponível gratuitamente no endereço: https://linguakit.com/pt/analise-completa. Acesso em: 06 set 2018.
} 
Cabré (1999: 25) explica que em “[...] uma obra terminológica, a presença de nomes é quase exclusiva e a de verbos, adjetivos e locuções muito escassa". ${ }^{9}$ Para a autora, a presença quase que predominante da classe dos nomes, especificamente de substantivos, é uma clara evidência de uma especificidade das linguagens especializadas.

No que diz respeito a aspectos gerais dos termos encontrados nos corpora, é possível observar termos complexos, mudanças morfossintáticas e uso de siglas e outros elementos braquigráficos. No quadro a seguir, são apresentados alguns exemplos extraídos dos corpora desta análise:

Quadro 4: Formas da variação nos termos

\begin{tabular}{|c|c|c|}
\hline \multirow{2}{*}{ PROCESSOS } & \multicolumn{2}{|c|}{ EXEMPLOS } \\
\hline & Variante $1^{10}$ & Variável2 \\
\hline \multirow{3}{*}{ Variação Morfossintática } & Plantio Mecanizado & $\begin{array}{c}\text { Plantio de } \\
\text { mecanização }\end{array}$ \\
\hline & Plantio de cana & Plantio da cana \\
\hline & Cultivo Mecânico & Cultivo Mecanizado \\
\hline \multirow{3}{*}{$\begin{array}{c}\text { Simplificação de sintagmas } \\
\text { terminológicos }\end{array}$} & Palha de cana & Palha \\
\hline & $\begin{array}{l}\text { palhada de cana-de- } \\
\text { açúcar }\end{array}$ & Palhada \\
\hline & Sistema de Manejo & Manejo \\
\hline \multirow{3}{*}{$\begin{array}{l}\text { Variação dos elementos do } \\
\text { sintagma }\end{array}$} & Preparo do Solo & Preparo do Terreno \\
\hline & Plantio Tradicional & Plantio Convencional \\
\hline & Palhada da Cultura & Palhada de cana \\
\hline \multirow{3}{*}{ Heteronímia } & Cana-de-açúcar & Planta, variedade \\
\hline & Perfilhamento & Brotação \\
\hline & Canavial & Área \\
\hline
\end{tabular}

Fonte: elaboração própria

O quadro 4 apresenta a diversidade de formas como a variação é encontrada nos termos analisados no estudo e traz algumas formações que são comuns no universo discursivo especializado, sobretudo, quando se consideram os dois canais, a oralidade e a escrita. Há uma predominância de sintagmas terminológicos e há também reduções desses sintagmas (CABRÉ 1999; KRIEGER 2008). Fenômenos como as reduções de sintagmas e a heteronímia são muito comuns na fala especializada, no entanto também podem ser

\footnotetext{
${ }^{9}$ No original: "[...] en una obra terminológica, la presencia de nombre es casi exclusiva y la de verbos, adjetivos y locuciones muy escasa."

${ }^{10}$ A variante corresponde ao termo que aparece com maior frequência no corpus.
} 
observados nos textos escritos, como será apresentado adiante. De um ponto de vista morfológico, as denominações encontradas não eram constituídas por muitos termos complexos com mais de três elementos, embora seja possível observar alguns outros termos desse âmbito com mais de três, como rebrota de cana cortada, sistema de irrigação por aspersão, entre outros. Esses são encontrados em menor número nos corpora.

É interessante observar ainda nos corpora como essa variação denominativa se apresenta. Nesse sentido, é possível verificar, nos trechos de dois textos do corpus, a variação denominativa operando em diferentes sentidos, em especial, colaborando para a coesão textual e para a configuração do próprio texto especializado, tendo em vista que a presença de termos em um texto é um dos critérios para a configuração de um texto especializado (CIAPUSCIO 2003). Nesse sentido, é interessante averiguar as estratégias de introdução de um tema em um texto, que pode ser ancorado ou não ancorado (CINTRA; Penhavel 2018): no primeiro, apresenta-se uma forma nova para depois apresentar suas variações; no segundo, oscilam as formas novas e conhecidas sem uma ordem específica. Essa introdução e variação de informações na constituição de um texto estão relacionadas à variação denominativa.

Considera-se que as atividades de coesão referencial são responsáveis pela progressão do texto por meio de introdução (ativação) e da reconstrução ou manutenção dos referentes textuais, chamados de objetos do discurso. Através dessas operações sociocognitivasinteracionais, os objetos do discurso possibilitam a constituição da memória discursiva dos interlocutores, levando ao estabelecimento de um determinado modelo textual. (CINTRA; PENHAVEL 2018: 221, grifos originais)

No trecho a seguir, observa-se um segmento do artigo de divulgação, em que o jornalista especialista no setor da cana-de-açúcar utiliza-se da variação denominativa para fechar uma cadeia de sentidos que opera simultaneamente para a simplificação do texto, a progressão textual e para a melhor compreensão do leitor. Inicia o parágrafo utilizando-se do termo "cobrimento das mudas" e, em seguida, usa o hiperônimo "operação" e o sinônimo "cobrição" para tratar de uma operação importante no plantio da cana:

0 <cobrimento das mudas> de cana na ocasião do plantio é executado em condições ótimas de temperatura e umidade do solo para proporcionar uma 
eficiente brotação. É nesta <operação> o momento de utilizar as tecnologias de controle de pragas e doenças como uso de inseticidas, nematicidas, fungicidas e estimulantes de germinação, que em muitas vezes apresentam fatores que restringem ou limitam a produção. Quando necessária, a recobrição é feita manualmente e deve ocorrer imediatamente após a <cobrição> para corrigir as falhas do cobridor ou pelas diferentes fases de umidade do solo durante a cobertura. A recobrição dos toletes salientes ao solo garante uma melhor condição de brotação das gemas.

No texto oral conferência, o especialista utiliza-se das variantes linguísticas sem muito se preocupar com a introdução do tema. Nesse sentido, a ativação é feita apenas para acionar a memória discursiva dos ouvintes.

A respeito da temática de $<$ palhada $>$. Então o primeiro projeto começou a ser desenvolvido com <palhada de cana-de-açúcar> foi uma parceria com a Petrobrás. Então a Petrobrás nos procurou, pediu, foi praticamente uma encomenda esse projeto. Nós temos o interesse em usar a <palha de cana-deaçúcar> e gostaríamos de saber o que vai acontecer com o campo caso a gente retire grande quantidade desse material.

Como se observa, a variação denominativa tem, entre outros objetivos, a própria naturalização e a construção do texto especializado. De acordo com Ciapuscio (2003), a ordem e o nível de particularização dos termos utilizados, isto é, quanto mais específico for o termo maior é o grau de especialização que ele apresenta, são elementos que dão importantes informações sobre um determinado texto e seu nível de especialização. Como nos exemplos apresentados no contexto de divulgação, a necessidade de apresentação e de explicação e, consequentemente, de utilização de sinônimos com alto e baixo nível de especificidade é próprio do contexto de divulgação, enquanto que, no texto mais especializado, termos mais acadêmicos e específicos aparecem com maior frequência, sobretudo devido ao contexto em que o discurso é veiculado e à audiência a quem o texto é destinado. Mesmo nesse contexto, é importante esclarecer que, como se observa no trecho do texto mais especializado (conferência), podem aparecer termos mais genéricos e paráfrases. Para Ciapuscio (2003: 54), “[...] os diferentes contextos discursivos determinam os conteúdos conceituais especificados no texto" ${ }^{11}$.

\footnotetext{
${ }^{11}$ No original: "[...] diferentes contextos discursivos determinan los contenidos conceptuales especificados en el texto".
} 


\section{Últimas Considerações}

Conforme foi observado ao longo deste estudo, a variação denominativa é uma realidade no discurso especializado do universo agrícola da cana-de-açúcar. Constatar a presença de variação denominativa neste estudo mostra que, em diferentes contextos comunicativos, a variação tem uma função que é comunicativa e que se adapta às diferentes circunstâncias em que acontece. Conforme se pôde observar ao longo da análise, os gêneros especializados artigo científico e apostila (com maior número de palavras) não apresentaram um número muito superior de variação, considerando outros gêneros com menor número de palavras, como o artigo de divulgação e entrevista; apesar de a apostila ter apresentado o maior número de conceitos polidenominativos, não foi uma diferença considerável em relação aos outros gêneros.

$\mathrm{Na}$ amostra investigada, há predominância de substantivos e verbos e de sintagmas nominais formados por até 3 elementos. Entre os sintagmas terminológicos complexos, só foram encontrados sintagmas formados a partir da estrutura S+ADJ e S+SP. A simplificação das formas lexicais encontrada nos corpora é indício de uma área mais bem estruturada e normatizada, em que os conceitos encontram mais formas lexicalizadas do que em processo de lexicalização.

Como foi observado, a variação denominativa em um discurso especializado apresenta um conjunto de funções que são comunicativas, textuais e contextuais, e isso deve ser considerado no tratamento e reconhecimento das formas lexicais de um discurso especializado, sobretudo quando se faz uma análise terminológica levando em consideração as teorias descritivas da Terminologia.

Os resultados deste trabalho apontam para uma possibilidade de análise de um universo especializado considerando os fatores funcionais que condicionam a variação em suas diferentes condições. A partir do momento em que se entende que toda variação denominativa ou conceitual é condicionada por fatores externos e internos de um discurso especializado, é necessário que se conheçam esses fatores e se saiba de que modo eles cooperam e colaboram para a variação; desse modo, será possível ampliar as informações acerca do funcionamento real do discurso em um campo especializado. 


\section{Referências Bibliográficas}

CIAPUSCIO, E. Textos Especializados y Terminologia. Barcelona: Institut Universitari de Lingüística Aplicada, 2003.

CABRÉ, M. T. La Terminología: representación y comunicación. Barcelona: Institut Universitari de Lingüística Aplicada, 1999.

CABRÉ, M. T. Theories of terminology: their descriptions, prescriptions and explanations. Terminology, n. 9, v. 2, p. 193-199, 2003.

Cintra, M. R.; Penhavel, E. Linguística Textual e Semântica. In. Souza, E. R. F.; Penhavel, E.; CINTRA, M. R. Linguística Textual: interfaces e delimitações/ homenagem a Ingedore Grünfeld Villaça Koch. São Paulo: Contexto, 2017, p. 211-232.

FREIXA, J. La variació terminològica: anàlisi de la variació denominativa en textos de diferent grau d'especialització de l'àrea de medi ambient. Tese (Doutorado em Lingüística Aplicada), Universidad de Barcelona, Barcelona, 2002.

FREIXA, J. Causes of denominative variation in terminology: a typological proposal. Terminology. v. 12, n. 1, p. 51-77, 2006.

FREIXA, J. Otra vez sobre las causas de la variación denominativa. Debate Terminológico, n. 9, v.1, p. 38-46, 2013.

FEtTER, G. L. Divulgação tecnológica para agricultores familiares: análise de terminologias sob a ótica da lingüística sistêmico-funcional. Tese (doutorado em letras) Programa de Pós-Graduação em Letras, Universidade Federal do Rio Grande do Sul, 2017.

GaUdIN, F. Pour une socioterminologie: des poblèmes semantiques aux pratiques institutionelles. Rouen: Université de Rouen, 1993.

Gamallo, P.; GarCiA, M. LinguaKit: uma ferramenta multilíngue para análise linguística e a extração de informações. LínguaMática, v. 09, n. 1, p. 19-28, 2017.

HalLidAY, M. A. K. Spoken and written language. Oxford: Oxford Express, 1990.

KoCH, I. V. G. Introdução à Linguística Textual. São Paulo: Contexto, 2015.

KoCH, I. V. G. Especificidades do texto falado. In: Jubran, C. S. (org.). A construção do texto falado: gramática do português culto falado no Brasil. São Paulo: Contexto, 2015b, p.39-46.

Krieger, M. G. Terminologia revisitada. DELTA, v. 16, n. 2, 2000, p. 209-228. http://dx.doi.org/10.1590/S0102-44502000000200001 
KRIEGER, M. G. Terminologia e seus objetos de investigação. In: X SIMPOSIO IBEROAMERICANO DE TERMINOLOGÍA, 2008, Montevideo. Actas.... Montevideo: RITERM, 2008. p. 1-8.

Kocourek, R. Texts et terms. Meta, v. 36, n. 1, p. 71-76, 1992. Doi: http://id.erudit.org/iderudit/003330ar

SAGER, J. C. In Search of a foundation: towards a theory of the term. Terminology, v. 5, n. 1, p. 41-57, 1999.

SEGHEZZI, N. Variación Terminológica y canal de comunicación: estudio contrastivo de textos especializados escritos y orales sobre lingüística. Tese (Doutorado em Lingüística Aplicada), Institut Universitari de Lingüística Aplicada, Barcelona, 2011.

Recebido em: 17/02/2020

Aceito em: 02/12/2020

Publicado em dezembro de 2020 